Cite this: Phys. Chem. Chem. Phys., 2011, 13, 12906-12911

\title{
Multichromophore light harvesting in hybrid solar cells
}

\author{
Jayasundera Bandara, ${ }^{a b}$ Katja Willinger $^{a}$ and Mukundan Thelakkat ${ }^{* a}$ \\ Received 25th May 2011, Accepted 31st May 2011 \\ DOI: $10.1039 / \mathrm{c} 1 \mathrm{cp} 21697 \mathrm{j}$
}

A new technologically relevant method for multichromophore sensitizing of hybrid blend solar cells is presented. Two dyes having complementary absorption in the UV-visible regions are individually adsorbed on nanocrystalline $\mathrm{TiO}_{2}$ powder. These dyed $\mathrm{TiO}_{2}$ nanoparticles are blended with an organic hole-conductor (HC) Spiro-OMeTAD in desired compositions and applied on a conducting substrate by doctor-blading at room temperature to fabricate multichromophore-sensitized hybrid blend solar cells. The external quantum efficiency (EQE) of the single hybrid layer system fabricated with two dyes, that absorb mainly UV (TPD dye) and visible regions (Ru-TPA-NCS dye), exhibited a clear panchromatic response with the sum of the EQE characteristics of each single dye cell. The first results of a multichromophore-sensitized solid-state solar cell showed $J_{\mathrm{sc}}$ of $2.1 \mathrm{~mA} \mathrm{~cm}{ }^{-2}, V_{\mathrm{oc}}$ of $645 \mathrm{mV}$, FF of $47 \%$ and efficiency of $0.65 \%$ at $\mathrm{AM} 1.5 \mathrm{G}, 100 \mathrm{~mW} \mathrm{~cm}^{-2}$ illumination intensity. The $J_{\mathrm{sc}}$ of the multichromophore cell is the sum of the individually dyed solar cells. The process described here is technically very innovative and very simple in procedure. It has potentials to be adopted for panchromatic sensitization using more than two dyes in a single hybrid layer or layer-wise fabrication of a tandem structure at room temperature.

\section{Introduction}

There are different concepts for realizing solid-state organicinorganic hybrid solar cells. The methods range from an adaptation of dye-sensitized solar cells in which a solid-state hole conductor is filled into a previously sintered mesoporous titania network ${ }^{1-3}$ up to simple blending of polymeric hole conductors and metal oxides $\left(\mathrm{TiO}_{2}, \mathrm{ZnO} \text {, etc. }\right)^{4,5}$ or inorganic semiconductors (CdSe, $\mathrm{CdS}$, etc.). ${ }^{6}$ Other attempts include an in situ synthesis of the inorganic semiconductor in a polymer hole conductor matrix. ${ }^{7,8}$ The first method of filling a mesoporous layer suffers from inefficient filling, especially with polymeric hole conductors, whereas blending usually results in low percolation for the electron transport via particles. Another issue in hybrid solar cells is how to increase the light harvesting. Ideally, the dye should be panchromatic, that is, it absorbs photons over the entire visible region of the solar spectrum while maintaining sufficient thermodynamic driving force for both the electron injection and dye regeneration process. ${ }^{9,10}$ The single ideal dye that absorbs all visible light and smoothly transfers electrons is very difficult to realize. ${ }^{11}$ Molecular design of such an ideal sensitizer to absorb visible light of all colors presents a challenging task. The problem is

\footnotetext{
${ }^{a}$ Applied Functional Polymers, Department of Macromolecular Chemistry, University of Bayreuth, Germany.

E-mail: mukundan.thelakkat@uni-bayreuth.de;

Fax: + 49-921-553109; Tel: + 49-921-553109

${ }^{b}$ Institute of fundamental Studies, Hantana Road, CP 20000, Kandy, Sri Lanka.E-mail: jayasundera@yahoo.com; Tel: +94812232002
}

that when using a single dye possessing a low band gap (usually low LUMO: lowest unoccupied molecular orbital) absorption spectrum, it is difficult to inject electrons from the dye to the n-type semiconductor because the LUMO of the dye approaches the conduction band of the semiconductor. To overcome this problem, several multichromophore light harvesting methods have been attempted. ${ }^{12,13}$ One such attempt was the co-sensitization using a cocktail of dyes with complementary absorption. ${ }^{14-17}$ The major problem in co-sensitization is that the number of free sites available on the titania surface for the dye attachment is limited and unfavorable adsorption and desorption interactions between two dye molecules often resulted in decrease in photovoltaic performances. On the other hand, tandem dye-sensitized solar cells (DSSC) have been introduced in liquid electrolyte based systems to minimize the unfavorable dye-dye interactions present in co-sensitized devices. ${ }^{18-20}$ Though tandem DSSC is a promising approach for multichromophore devices, the fabrication of monolithic tandem solar cells remains largely challenging. ${ }^{11,21}$ Furthermore the present high temperature preparation methods limit the fabrication of hybrid devices on a flexible substrate as high temperature sintering is usually necessary for the preparation of mesoporous metal oxide (e.g. $\left.\mathrm{TiO}_{2}\right)$ electrodes. Moreover, the second mesoporous $\mathrm{TiO}_{2}$ layer that is necessary on the first dyed $\mathrm{TiO}_{2}$ layer to fabricate the tandem device cannot be prepared by the same method. To overcome these difficulties, novel concepts of multichromophore sensitization and room temperature fabrication of hybrid solar cells are urgently required. 


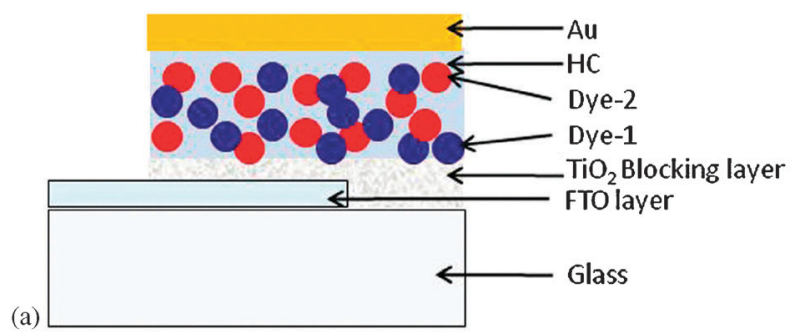

(b)

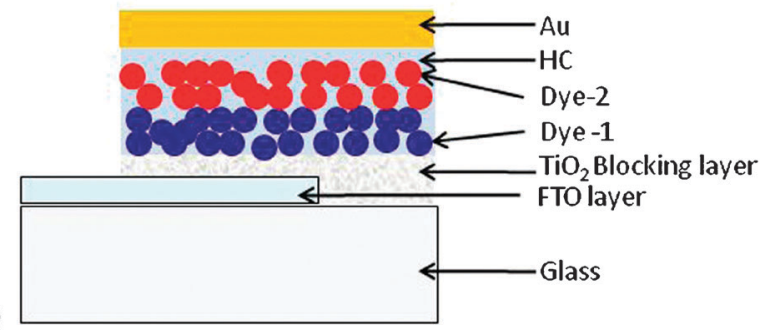

Fig. 1 Schematic diagram of a multichromophore sensitized hybrid solar cell with (a) randomly and (b) layer-wise dyed- $\mathrm{TiO}_{2}$ thin films for the case of two different dyes.

In this investigation we address most of the above issues encountered in this field and present a new fabrication concept for multichromophore light harvesting in hybrid devices using $\mathrm{TiO}_{2}$ nanocrystals and an organic hole conductor. The dyes 1, 2 , etc. (in principle we can use several dyes as we wish) having complementary absorption in the $\mathrm{UV}$-visible regions are individually adsorbed on nanocrystalline $\mathrm{TiO}_{2}$ powder separately. These dyed $\mathrm{TiO}_{2}$ particles are mixed with an organic holeconductor (e.g. Spiro-OMeTAD or any p-type polymer) in any desired composition and this blend was applied on a conducting substrate by the doctor-blading method at room temperature. Finally an additional hole injection smoothing layer (PEDOT : PSS) was coated onto the blend layer. The two possible device structures are schematically shown in Fig. 1. Thus these solar cells can be fabricated either using a random mixture of differently dyed- $\mathrm{TiO}_{2}$ (Fig. 1a) or with subsequent layers of selectively dyed-TiO ${ }_{2}$ (Fig. 1b). The method described here is very simple and cost effective but technologically very relevant. The layer-wise fabrication of two differently dyed layers at room temperature can be extended to panchromatic (multichromophoric) sensitization using more than two dyes in a tandem structure. In the following section, the proof of principle is shown for (a) a single mixed dye hybrid device and (b) a two-dye layer-wise assembly, while the latter method can be adopted for tandem cells very easily. It is important to note that the active layers were prepared at ambient conditions using the doctor-blading method, which is suitable for flexible device fabrication on plastic substrates.

\section{Experimental method}

Titanium(Iv)bis(acetoacetonato)-di(isopropanoxylate) (TAA) (Aldrich), $\mathrm{TiO}_{2}$ (P25 Degussa), Spiro-OMeTAD (Merck) and PEDOT: PSS (Aldrich) were purchased and used as received. Glass substrates (Tec 8) covered with a fluorine-doped tin oxide (FTO) layer having sheet resistances of $8 \Omega$ per square were purchased from Hartford Glass Co. Inc., Indiana, USA.
The $\mathrm{TiO}_{2}$ blocking layer $\left(\mathrm{bl}-\mathrm{TiO}_{2}\right)$ was prepared by a spray pyrolysis deposition technique and the method has been discussed in detail by Peng et al. and hence only a brief account is mentioned here. ${ }^{22}$ The $\mathrm{TiO}_{2}$ precursor, TAA, diluted with ethanol to a concentration of $0.2 \mathrm{M}$ was used as the spraying solution and the pyrolysis was carried out at $400{ }^{\circ} \mathrm{C}$. After the required number of spraying cycles under optimized conditions were done, the substrates were annealed at $400{ }^{\circ} \mathrm{C}$ for another hour before cooling down to room temperature. The substrates were kept in an inert atmosphere for further layer preparation. A similar compact blocking layer may also be prepared under low temperatures using published methods in the literature. ${ }^{23,24}$

For multichromophore dye adsorption, two methods were employed; in the first case, dyes were adsorbed on $\mathrm{TiO}_{2}$ particles separately and the dyed particles were mixed later. In the second case, a mixture of dyes was adsorbed on $\mathrm{TiO}_{2}$ particles simultaneously. In both cases, similar solar cell efficiencies were observed. Therefore, to keep the fabrication method identical for all the experiments, we used the second method for the fabrication and the results from these are discussed in detail as described below. The syntheses of dye-1, (E)-2-cyano-3-(4-((4-methoxyphenyl)(4'-((4-methoxyphenyl) (phenyl)amino) biphenyl-4-yl)amino) phenyl) acrylic acid [TPD-dye], and dye-2, cis-di(iso-thiocyanato)(2,2'-bipyridyl4,4'-dicarboxylic acid)-(2,2'-bipyridyl-4,4' -bis(vinyl triphenylamine) ruthenium(II) [Ru-TPA-NCS], have been described elsewhere. $^{25,26}$ Dye-2 was dissolved in an equal mixture of tert-butanol and acetonitrile, while for dye 1, the same solvent mixture was used with the addition of $10 \%$ DMSO. For individual dye adsorption, $75 \mathrm{mg}$ of $\mathrm{TiO}_{2}$ powder was mixed with $7.5 \mathrm{ml}$ of $0.5 \mathrm{mM}$ solution of dye- 1 or dye- 2 separately. For multichromophore sensitization, $75 \mathrm{mg}$ of $\mathrm{TiO}_{2}$ powder was mixed with a dye mixture containing equimolar amounts of dye 1 and dye 2 in $7.5 \mathrm{ml}$ of $0.5 \mathrm{mM}$ concentration. All the suspensions were stirred well for dye adsorption for one hour and filtered to obtain dyed- $\mathrm{TiO}_{2}$ nanocrystals. After the physisorbed dye molecules were rinsed away by washing the dyed- $\mathrm{TiO}_{2}$ powder by the same solvent mixture, the samples were subsequently dried in air. To get pastes suitable for doctor-blading, $60 \mathrm{mg}$ of the respective dyed- $\mathrm{TiO}_{2}$ was stirred with $140 \mu \mathrm{HC}$ solution (containing additives) for 1-2 hours and the final paste was applied on the bl- $\mathrm{TiO}_{2}$ coated FTO substrates. $140 \mu \mathrm{l}$ of $\mathrm{HC}$ in chlorobenzene solution contain $48 \mathrm{mg}$ of Spiro-OMe-TAD, $6 \mathrm{mg}$ of tert-butylpyridine (tbp) and $5.1 \mathrm{mg}$ of $\mathrm{N}$-lithiofluoromethane sulfonamide (Li salt). Li salt solution was normally prepared separately by dissolving $17 \mathrm{mg}$ of $N$-lithiofluoromethane sulfonamide in $100 \mu \mathrm{l}$ of acetonitrile. This composition of the $\mathrm{HC}$ is maintained, but for optimization of solar cell performance, the concentration was varied. For obtaining randomly dyed- $\mathrm{TiO}_{2}$ thin films as shown in Fig. 1a, a mixture of dyes was adsorbed on $\mathrm{TiO}_{2}$ particles simultaneously and mixed with $\mathrm{HC}$ as explained earlier. To fabricate layer-wise devices (Fig. 1b), dye-1 coated $\mathrm{TiO}_{2}-\mathrm{HC}$ blend was first doctor-bladed on FTO glass and dried followed by dye- 2 coated $\mathrm{TiO}_{2}-\mathrm{HC}$ blend. On top of the active layer, a hole injection and smoothening layer of PEDOT:PSS was spin-coated. As a final step, a $40 \mathrm{~nm}$ Au-layer was vapor-deposited by sublimation in a vacuum chamber of BA 510 type from Balzers (Liechtenstein) under 
vacuum with the help of a mask with an active surface of $0.12 \mathrm{~cm}^{2}$.

The photovoltaic current-voltage measurements were carried out by a Keithley 6517 Source-Measure unit under AM 1.5 G conditions (Solar simulator-A grade from Newport). The intensity of the light was calibrated with a standard Si-reference cell from the Fraunhofer Institut für Solarenergie (ISE), Freiburg, as $100 \mathrm{~mW} \mathrm{~cm} \mathrm{~cm}^{-2}$. All efficiency values reported in this work were not corrected by the spectral mismatch factor. The IPCE values were measured using a lock-in amplifier (SR830, Stanford Research Systems) with a current preamplifier (SR570, Stanford Research Systems) under short-circuit conditions after illuminating the devices with monochromatic light from a Xenon lamp passing through a monochromator (Spectra-model). UV-Vis spectra were recorded with a Hitachi 3000 spectrometer. Surface morphology of $\mathrm{TiO}_{2}$ nanoparticles was examined using a LEO 1530 Gemini field emission scanning electron microscope (FE-SEM).

\section{Results and discussion}

Light absorption in a broad wavelength region by dye molecules is a prerequisite for high solar cell efficiency. However lack of such a single dye makes it necessary to use a mixture of two or more dyes for panchromatic sensitization of nanocrystalline $\mathrm{TiO}_{2}$. In this investigation we introduced a novel fabrication concept that avoids most of the problems encountered in fabrication of multichromophore sensitized solar cells. To prepare multichromophore sensitized solar cells, different dyes having complementary absorption in the UV-visible regions are adsorbed on nanocrystalline $\mathrm{TiO}_{2}$ powder and these dyed$\mathrm{TiO}_{2}$ particles are mixed with an organic hole-conductor Spiro-OMeTAD to get a suspension. Finally, this paste was applied on a conducting substrate by the doctor-blading method to fabricate thin film electrodes at room temperature. Fig. 1 depicts schematically the different ways of fabrication of an active layer, whereas Fig. 2 shows the major steps of preparation. For this experiment, we used two dyes, dye-1 (TPD-dye) and dye-2 (Ru-TPA-NCS).

Their molecular structures are shown in Fig. 3 and their absorption spectra in DMSO solution are compared with that of the equimolecular mixture in Fig. 4. The TPD-dye absorbs mainly in the $\mathrm{UV} /$ blue region of the solar spectrum having absorption maximum around $400 \mathrm{~nm}$ and the color of the dye is yellow. The Ru-TPA-NCS absorbs mainly in the green visible region of the solar spectrum having absorption maximum at $550 \mathrm{~nm}$ and the color of the dye is dark brown. The dye mixture possesses the absorption contributions of the individual dyes and exhibits a broad absorption spectrum

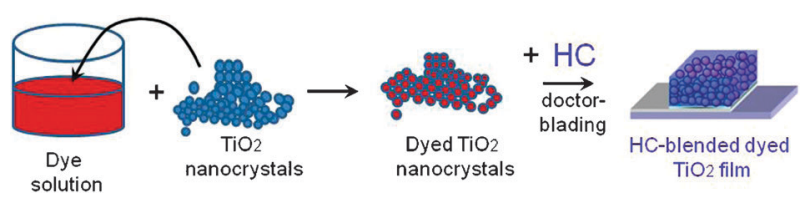

Fig. 2 Schematic sketch of the fabrication steps of active layer of the hybrid blend solar cell at room temperature.

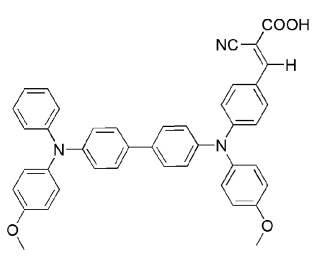

(a)

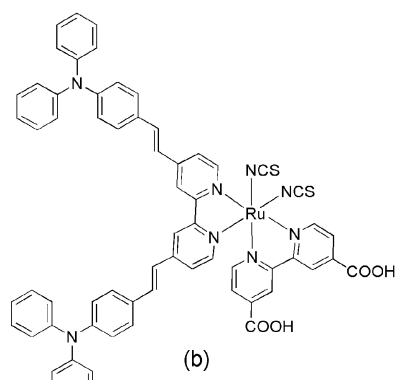

(b)
Fig. 3 Chemical structures of (a) dye-1: TPD-dye and (b) dye-2: Ru-TPA-NCS.

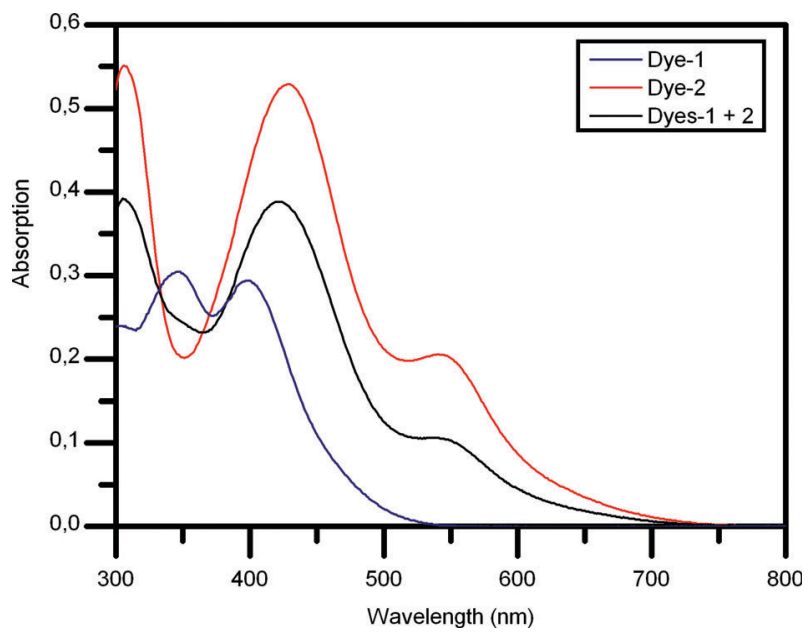

Fig. 4 UV-vis absorption spectra of dye-1 $\left(1.0 \times 10^{-5} \mathrm{M}\right)$, dye-2 $\left(1.0 \times 10^{-5} \mathrm{M}\right)$ and the mixture of dye- 1 and dye-2 $\left(0.5 \times 10^{-5} \mathrm{M}\right.$ each $)$ in DMSO solution.

covering from $300 \mathrm{~nm}$ to $600 \mathrm{~nm}$. The molar extinction coefficient for the absorption maxima for the TPD-dye at $400 \mathrm{~nm}$ is $27500 \mathrm{M}^{-1} \mathrm{~cm}^{-1}$, whereas Ru-TPA-NCS has a value of $20500 \mathrm{M}^{-1} \mathrm{~cm}^{-1}$ at $544 \mathrm{~nm}$. The former corresponds to the $\pi-\pi^{*}$ transitions of the conjugated dye molecule, whereas the latter arises from an MLCT transition.

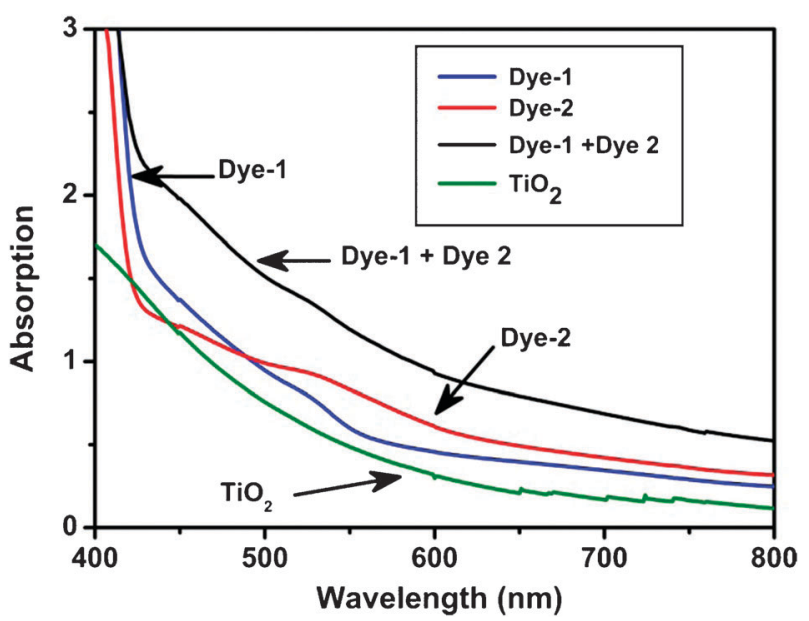

Fig. 5 UV-vis spectra of different active layers obtained by dye adsorption on $\mathrm{TiO}_{2}$ nanoparticles compared with the pristine $\mathrm{TiO}_{2}$. 

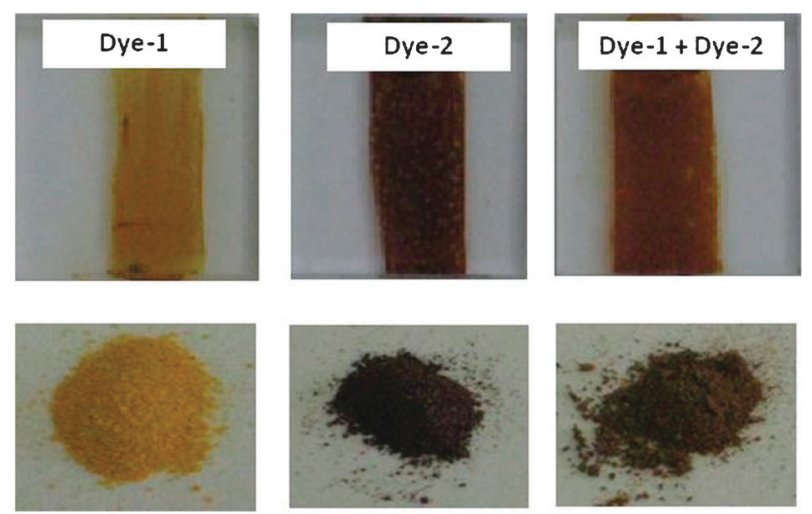

Fig. 6 Images of various dye coated $\mathrm{TiO}_{2}$ thin films on FTO glass (top) and dyed $\mathrm{TiO}_{2}$ nanocrystals (bottom).

The solid-state absorption of thin films of $\mathrm{TiO}_{2}$ nanoparticles on FTO glass coated with dye-1, dye- 2 and dye mixture are shown in Fig. 5, whereas the pictures of the dyed-electrodes and dyed particles are shown in Fig. 6.

A detailed description of dye-coating is given in the experimental part. In all the three cases, the amount of dyes used to absorb on to a definite amount of nanocrystals $(75 \mathrm{mg})$ was completely adsorbed and the supernatant solution was colorless. As absorbed on titania, the absorption peaks of Ru-TPA-NCS and TPD dyes are blue shifted and exhibit a broadened spectrum compared to those in DMSO solution. This implies the formation of dye aggregates on the $\mathrm{TiO}_{2}$ surface. However for the dye mixture, the absorption bands are not clearly visible owing to broadened absorption in the $300-600 \mathrm{~nm}$ region. The broadened absorption spectra on the $\mathrm{TiO}_{2}$ surface can enhance the light harvesting ability. The most striking feature of this dye adsorption method is the ability to incorporate high amounts of dyes on to the $\mathrm{TiO}_{2}$ surface. In a conventional liquid electrolyte DSSC, the reported adsorbed dye amount is in the range of $10^{16-19}$ molecules per $\mathrm{cm}^{2},{ }^{27,28}$ however in our case the adsorbed dye amount is in the range of $10^{20-21}$ molecules per $\mathrm{cm}^{2}$ which is roughly two orders of magnitude higher than the reported adsorbed dye amounts on mesoporous $\mathrm{TiO}_{2}$ thin films. As explained above, the co-adsorption or multi-adsorption of the dyes on $\mathrm{TiO}_{2}$ electrodes led to an efficient light harvesting over a wide spectrum region covering the whole UV-visible part which is a desirable feature for solar cells.

The power conversion efficiencies of single dye and multichromophore sensitized photovoltaic devices are shown in Fig. 7. For these experiments, spiro-OMeTAD concentration was kept at $282 \mathrm{mg} \mathrm{ml}^{-1}$ and $170 \mu \mathrm{l}$ of the $\mathrm{HC}$ solution was mixed with $60 \mathrm{mg}$ of dyed- $\mathrm{TiO}_{2}$. This results in a $\mathrm{TiO}_{2}$ : spiro-OMeTAD ratio of $1: 0.8(\mathrm{wt} / \mathrm{wt})$. The solar cell with dye-1 shows $J_{\mathrm{sc}}$ of 0.76 $\mathrm{mA} \mathrm{cm}{ }^{-2}, V_{\mathrm{oc}}$ of $750 \mathrm{mV}, \mathrm{FF}$ of $45 \%$ and $0.15 \%$ efficiency, while devices using dye-2 show $J_{\mathrm{sc}}$ of $0.64 \mathrm{~mA} \mathrm{~cm}{ }^{-2}, V_{\mathrm{oc}}$ of $620 \mathrm{mV}, \mathrm{FF}$ of $59 \%$ and $0.34 \%$ efficiency. The multi-dye sensitized device shows $J_{\mathrm{sc}}$ of $1.46 \mathrm{~mA} \mathrm{~cm}{ }^{-2}, V_{\mathrm{oc}}$ of $715 \mathrm{mV}$, FF of $51 \%$ and an efficiency of $0.54 \%$.

It is clearly evident that the efficiency and $J_{\mathrm{sc}}$ of the multidye sensitized solar cell are equal to or higher than the collective efficiencies and $J_{\mathrm{sc}} \mathrm{s}$ of the individual solar cells, respectively. The most striking feature of multi-sensitized solar

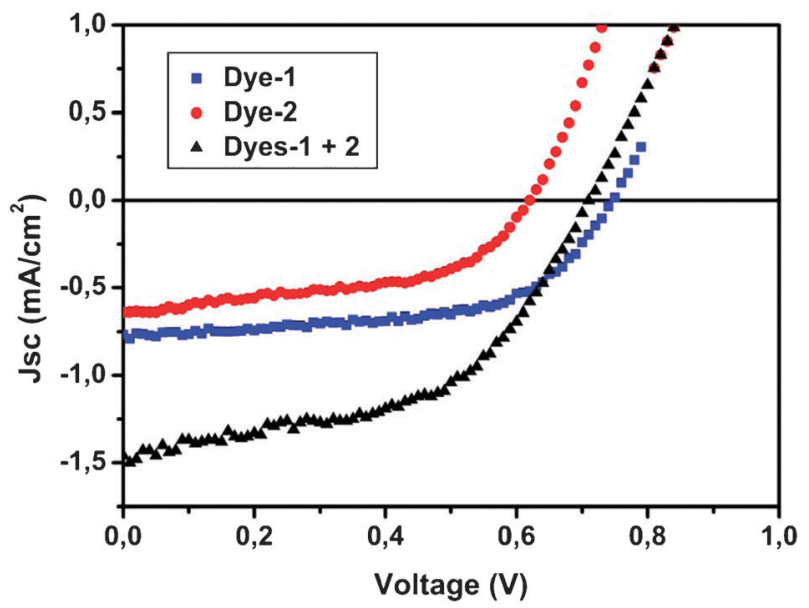

Fig. $7 \quad I-V$ characteristics of devices for dye-1, dye-2 and for the dye mixture at illumination intensity of $100 \mathrm{~mW} \mathrm{~cm} \mathrm{~cm}^{-2}$ at $1.5 \mathrm{G} \mathrm{AM}$ condition. The $\mathrm{TiO}_{2}$ : spiro-OMeTAD composition is $1: 0.8$ (wt/wt).

cell is that it adds up the currents of the individual contributing cells as if in a parallel connected tandem cell. Thus the feasibility of efficient multichromophore light harvesting is demonstrated here. For the sequentially layer-wise deposited devices (see Fig. 1b), we observed a similar performance improvement $\left(J_{\mathrm{sc}} \text { of } 1.62 \mathrm{~mA} \mathrm{~cm}\right)^{-2}, V_{\mathrm{oc}}$ of $710 \mathrm{mV}, \mathrm{FF}$ of $52 \%$ and an efficiency of $0.59 \%$ ). This clearly supports the adaptability of the fabrication method described here towards tandem solar cells. Even though the absolute device efficiency reported in these first results is not very high compared to reported values in solid-state hybrid devices, the photovoltaic performance can be improved further as described below.

The IPCE spectra of devices with single dye and multi-dyes plotted as a function of excitation wavelength are presented in Fig. 8. For the individual dye devices, the photocurrent action spectra were found to match the absorption spectra of the individual dyes. The Ru-TPA-NCS dye device shows the maximum value of IPCE at $550 \mathrm{~nm}$ and the TPA-dye device shows the maximum IPCE at $430 \mathrm{~nm}$ which corresponds to the characteristic absorption of Ru-TPA-NCs and TPD dyes, respectively.

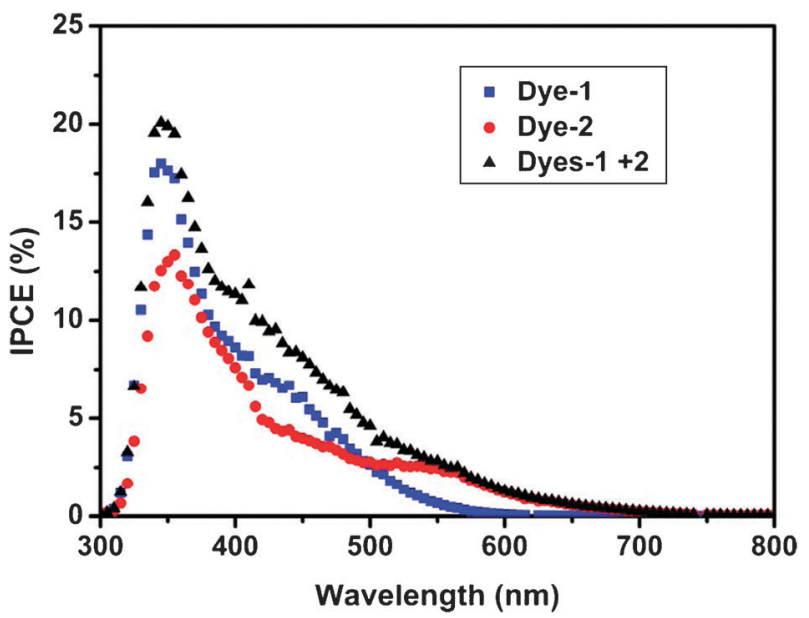

Fig. 8 IPCE spectra of devices with individual dye-1, dye-2 and dye mixture for the active layer prepared containing a $\mathrm{TiO}_{2}$ : spiro-OMeTAD composition of $1: 0.8(\mathrm{wt} / \mathrm{wt})$. 
Similarly, for the multichromophore-sensitized device, the photocurrent action spectrum was found to match the absorption spectra of the mixtures of the two dyes with two maximum IPCE values at $550 \mathrm{~nm}$ and $430 \mathrm{~nm}$. It is also clearly noticeable that the multichromophore-sensitized device exhibits higher IPCE in the 300-600 nm region than any single-dye sensitized devices though the adsorbed amount of each dye is only half the amount in the multichromophoresensitized device. Such a cooperative effect can be assigned to effective compact coverage of the $\mathrm{TiO}_{2}$ surface by the presence of more dye molecules and the enhanced charge injection due to formation of dye aggregates. This shows that the multisensitization using two dyes investigated here extended the spectral response to the UV and visible domains and consequently enhanced the photocurrent and photovoltaic performance. The advantage using this method is that it has the potential to incorporate several dyes in a single layer electrode to cover the whole UV-visible-IR region.

We observed that the solar cell performance is highly dependent on the weight ratio of $\mathrm{TiO}_{2}$ : spiro-OMeTAD. This can be expected since the composition decides the charge transfer and charge transport efficiencies. Especially the charge percolation via the nanocrystals in a nanocrystals-organic blend depends on the connectivity of the particles. The $I V$ characteristics of the solar cells for different $\mathrm{TiO}_{2}$ : spiro-OMeTAD ratios in the blend are shown in Fig. 9 and Table 1. It can be observed that the best solar cell performance was obtained when the $\mathrm{TiO}_{2}$ : spiro-OMeTAD ratio is equal to $1: 0.6$ and observed $V_{\mathrm{oc}}, J_{\mathrm{sc}}, \mathrm{FF}$ and efficiency are $645 \mathrm{mV}, 2.1 \mathrm{~mA} \mathrm{~cm}{ }^{-2}, 47 \%$ and $0.65 \%$, respectively.

It is further interesting to study the bulk morphology of the active layer prepared by blending dyed- $\mathrm{TiO}_{2}$ and $\mathrm{HC}$ under ambient conditions. To study especially the distribution of dyed$\mathrm{TiO}_{2}$ particles in the blended system, we investigated the crosssections of blended devices by SEM. Fig. 10 shows the SEM images of these systems with the different $\mathrm{TiO}_{2}$ : spiro-OMeTAD ratios (Fig. 10a-c) and for the purpose of comparison, we have included the SEM of the double layer device in Fig. 10d as well. In all cases, the $\mathrm{HC}$ completely covers the dyed- $\mathrm{TiO}_{2}$ nanoparticles in the blended system as shown in Fig. 10a-c for

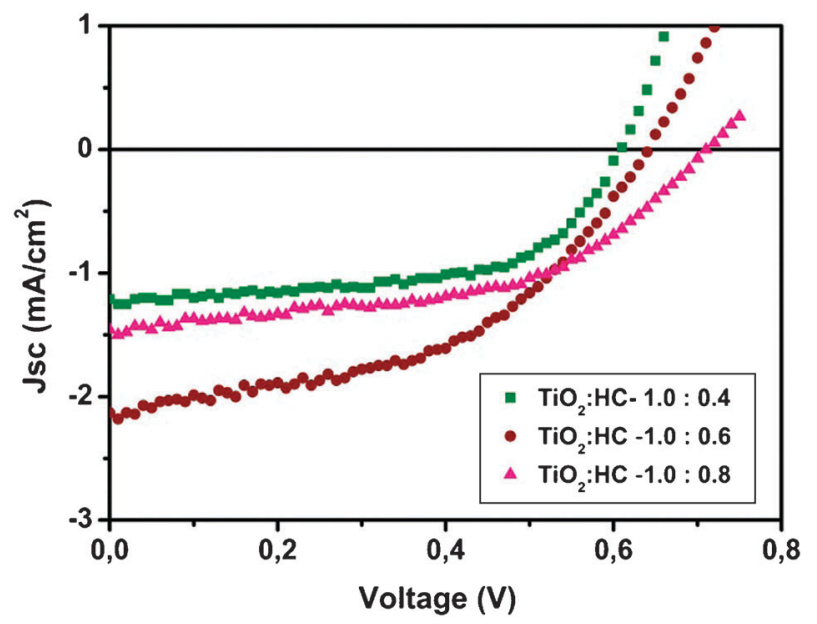

Fig. $9 I-V$ characteristics of devices with a dye mixture for the

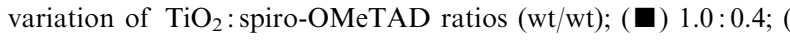
$1.0: 0.6$; and $(\boldsymbol{\Delta}) 1.0: 0.8$.
Table 1 Device parameters for the solar cells with different compositions of $\mathrm{TiO}_{2}$ : spiro-OMeTAD (wt/wt)

\begin{tabular}{lllll}
\hline $\begin{array}{l}\mathrm{TiO}_{2}: \text { spiro-OMeTAD } \\
(\mathrm{wt} / \mathrm{wt})\end{array}$ & $\begin{array}{l}V_{\mathrm{oc}} \\
(\mathrm{V})\end{array}$ & $\begin{array}{l}J_{\mathrm{sc}} \\
\left(\mathrm{mA} \mathrm{cm} \mathrm{cm}^{-2}\right)\end{array}$ & $\begin{array}{l}\mathrm{FF} \\
(\%)\end{array}$ & $\begin{array}{l}\mathrm{PCE}(\eta) \\
(\%)\end{array}$ \\
\hline $1: 0.4$ & 0.71 & 1.46 & 51 & 0.53 \\
$1: 0.6$ & 0.64 & 2.13 & 47 & 0.65 \\
$1: 0.8$ & 0.66 & 1.14 & 57 & 0.44 \\
\hline
\end{tabular}
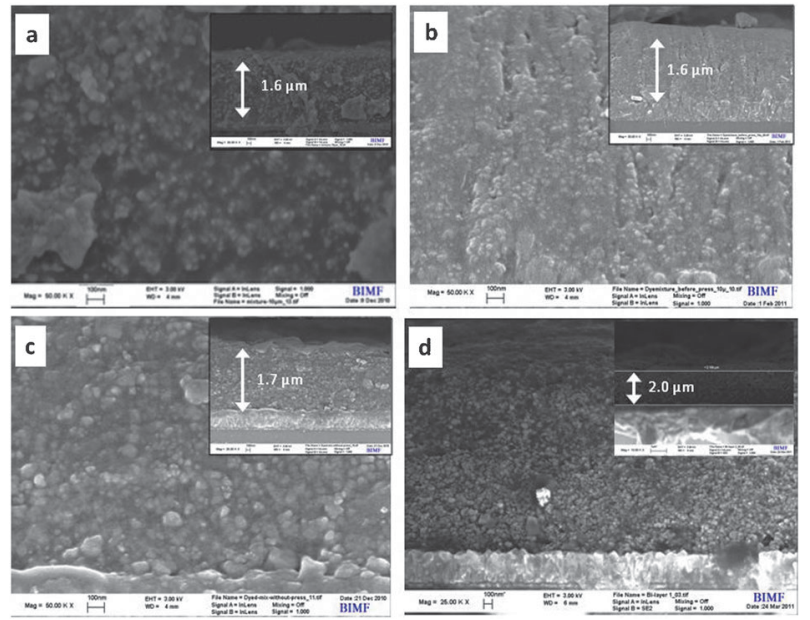

Fig. 10 Cross sectional SEM images of solar cells with different $\mathrm{TiO}_{2}$ : spiro-OMeTAD (wt/wt) compositions of (a) $1.0: 0.4$, (b) $1.0: 0.6$, (c) $1.0: 0.8$ and (d) cross sectional image of a bi-layer device. The insets show the complete cell cross-section with respective thickness of active layers.

$\mathrm{TiO}_{2}$ : spiro-OMeTAD ratios of $1: 0.4,1: 0.6$ and $1: 0.8$, respectively. It is evident that the interconnections of the $\mathrm{TiO}_{2}$ particles are different for different amounts of spiro-OMeTAD used. Analyses of the cross section SEM images of different $\mathrm{TiO}_{2}$ : spiro-OMeTAD ratios revealed that more space is filled by the spiro-OMeTAD in the case of high spiro-OMeTAD amount (Fig. 10c) resulting in dismal contact between $\mathrm{TiO}_{2}$ particles that leads to inefficient electron transport. However, when the spiro-OMeTAD concentration is low (Fig. 10a), space is filled mostly by $\mathrm{TiO}_{2}$ particles giving better electron paths, but less amount of spiro-OMeTAD may cause weak charge generation and negatively influences the hole transport. As mentioned earlier, thus the best solar cell performance was observed for the $\mathrm{TiO}_{2}$ : spiro-OMeTAD ratio of $1: 0.6$ and as shown in Fig. 10b, packing of $\mathrm{TiO}_{2}$ particles and amount of spiro-OMeTAD are balanced here, which facilitates an optimum device performance. Still an improved percolation via interconnected particles is not yet achieved, which requires additional engineering methods such as pressing or lamination. It is common that in conventional dye-sensitized devices, a mesoporous layer is fabricated at high temperature $\left(400-500{ }^{\circ} \mathrm{C}\right)$ and the dye is adsorbed afterwards and finally spiro-OMeTAD is filled in the pores of the mesoporous $\mathrm{TiO}_{2}$ electrode. Pore-filling of spiro-OMeTAD is a common problem in these devices and incomplete filling of $\mathrm{HC}$ in pores resulted in lower solar cell performance and poor dye regeneration leading to dye degradation. ${ }^{29-32}$ On the other hand, the blended system we described in this investigation does not suffer from this bottleneck. 
The above observations suggest the importance of having an optimum $\mathrm{TiO}_{2}$ : spiro-OMeTAD ratio to facilitate charge percolation and good device performance. Despite the fact that we could achieve an efficient interface area by blending the $\mathrm{HC}$ and the dyed $\mathrm{TiO}_{2}$ particles, it appeared that the limiting factor of these blended solar cells is the weak contact between $\mathrm{TiO}_{2}$ particles which hinders smooth electron transport. To verify this hypothesis and to enhance electron transport, we introduced PCBM, an efficient organic electron transport material to the system. It is interesting to note that the introduction of PCBM to the blended system resulted in increase in $J_{\mathrm{sc}}$ to $3.6 \mathrm{~mA} \mathrm{~cm} \mathrm{~m}^{-2}$

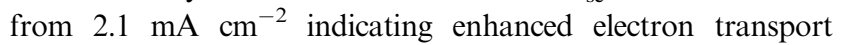
(since the absorption due to PCBM is negligible).

Though various types of new organic hole-conductors with higher charge carrier mobility have been reported recently, it is known that their difficulty in efficient pore-filling and wetting of the dyed- $\mathrm{TiO}_{2}$ layer in the conventional fabrication method of filling a porous titania layer hinders the real progress of the solid-state hybrid devices with new HCs. Hence the blended system described in this investigation opens up new venues for the exploration of various new HCs for solid-state hybrid devices. Additionally, since a blended system can be adopted very easily to introduce a second layer on top of the first device without disturbing the first layer, this method is more suitable for fabrication of monolithic hybrid tandem solar cells.

\section{Conclusion}

We have developed a facile method to fabricate multichromophore sensitized hybrid blend devices using a solution casting process that avoids high temperature sintering steps. Efficient charge separation, transport and collection could be achieved in this dyed- $\mathrm{TiO}_{2}$-spiro-OMeTAD blend system. An advantage of this method is that desired amounts and compositions of complementary dye-coated titania powders can be loaded onto a single hybrid layer or in several sequential layers by placing them on top of each other without disturbing the previous deposited layers. In this way the light harvesting can be complementarily improved leading to additive contributions in current and efficiency. Thus there is a high potential for the realization of monolithic tandem cells with complementary absorption using this fabrication method. We believe that this process of fabricating the dyed- $\mathrm{TiO}_{2}$-spiro-OMeTAD blend devices will be a promising method to harvest a wider range of solar spectra and the concept is applicable to any HCs. Insufficient contacts between $\mathrm{TiO}_{2}$ particles still limit the electron transport that lowers the efficiency. We believe that this issue can be surmounted by introducing additional electron pathways to the system, by increasing the aspect ratio of the nanoparticles using nanorods/ nanowires, by optimizing the composition of the blend and by additional engineering methods.

\section{Acknowledgements}

Jayasundera Bandara would like to acknowledge the financial support from the NRC grant (Grant No. 07-46) and
Alexander von Humboldt Foundation. We also acknowledge financial support from DFG (SFB 840).

\section{References}

1 H. J. Snaith, A. J. Moule, C. Klein, K. Meerholz, R. H. Friend and M. Gratzel, Nano Lett., 2007, 7, 3372.

2 S. Kolemen, Y. Cakmak, S. Erten-Ela, Y. Altay, J. Brendel, M. Thelakkat and E. U. Akkaya, Org. Lett., 2010, 12, 3812.

3 C. S. Karthikeyan and M. Thelakkat, Inorg. Chim. Acta, 2008, 361, 635 .

4 W. J. E. Beek, M. M. Wienk and R. J. Janssen, Adv. Mater., 2004, 16, 1009.

5 J. Boucle, P. Ravirajana and J. Nelson, J. Mater. Chem., 2007, 17, 3141 .

6 W. U. Huynh, J. J. Dittmer and A. P. Alivisatos, Science, 2002, 295, 2425.

7 S. D. Oosterhout, M. M. Wienk, S. S. van Bavel, R. Thiedmann, L. J. A. Koster, J. Gilot, J. Loos, V. Schmidt and R. A. J. Janssen, Nat. Mater., 2009, 8, 818.

8 H. C. Leventis, S. P. King, A. Sudlow, M. S. Hill, K. C. Molloy and S. A. Haque, Nano Lett., 2010, 10, 1253.

9 A. Islam, H. Sugihara, M. Yanagida, K. Hara, G. Fujihashi, Y. Tachibana, R. Katoh, S. Murata and H. Arakawa, New J. Chem., 2002, 26, 966.

10 M. Guo, P. Diao, Y. J. Ren, F. Meng, H. Tian and S.-M. Cai, Sol. Energy Mater. Sol. Cells, 2005, 888, 23.

11 J. Yum, E. Baranoff, S. Wenger, Md. K. Nazeeruddin and M. Grätzel, Energy Environ. Sci., 2011, 4, 842.

12 A. Islam, H. Sugihara and H. Arakawa, J. Photochem. Photobiol., A, 2003, 158, 131.

13 T. Funaki, M. Yanagida, N. Onozawa-Komatsuzaki, K. Kasuga, Y. Kawanishi and H. Sugihara, Chem. Lett., 2009, 38, 62.

14 R. Y. Ogura, S. Nakane, M. Morooka, M. Orihashi, Y. Suzuki and K. Noda, Appl. Phys. Lett., 2009, 94, 073308.

15 M. Guo, P. Diao, Y. J. Ren, F. Meng, H. Tian and S. M. Kai, Sol. Energy Mater. Sol. Cells, 2005, 88, 23.

16 K. Sayama, S. Tsukagoshi, T. Mori, K. Hara, Y. Ohga, A. Shinpou, Y. Abe, S. Suga and H. Arakawa, Sol. Energy Mater. Sol. Cells, 2003, 80, 47.

17 K. Lee, S. W. Park, M. J. Ko, K. Kim and N. G. Park, Nat. Mater., 2009, 8, 665.

18 W. Kubo, A. Sakamoto, T. Kitamura, Y. Wada and S. Yanagida, J. Photochem. Photobiol., A, 2004, 164, 33.

19 M. Dürr, A. Bamedi, A. Yasuda and G. Nelles, Appl. Phys. Lett., 2004, 84, 3397.

20 M. Murayama and T. Mori, Thin Solid Films, 2008, 516, 2716.

21 M. J. Scott, J. J. Nelson, S. Caramori, C. A. Bignozzi and C. M. Elliott, Inorg. Chem., 2007, 46, 10071.

22 B. Peng, G. Jungmann, C. Jäger, D. Haarer, H.-W. Schmidt and M. Thelakkat, Coord. Chem. Rev., 2004, 248, 1479.

23 S. Cho, K. Lee and A. J. Heeger, Adv. Mater., 2009, 21, 1941.

24 M. R. Lilliedal, A. J. Medford, M. V. Madsen, K. Norrman and F. C. Krebs, Sol. Energy Mater. Sol. Cells, 2010, 94, 2018.

25 C. S. Karthikeyan, H. Wietasch and M. Thelakkat, Adv. Mater., 2007, 19, 1091.

26 K. Willinger, K. Fischer, R. Kisselev and M. Thelakkat, J. Mater. Chem., 2009, 19, 5364.

27 A. Peic, D. Staff, T. Risbridger, B. Menges, L. M. Peter, A. B. Walker and P. J. Cameron, J. Phys. Chem. C, 2011, 115, 613.

28 K.-J. Hwang, S.-H. Jung, D.-W. Park, S.-J. Yoo and J.-W. Lee, Curr. Appl. Phys., 2010, 10, S184.

29 I.-K. Ding, N. Tétreault, J. Brillet, B. E. Hardin, E. H. Smith, S. J. Rosenthal, F. Sauvage, M. Grätzel and M. D. McGehee, Adv. Funct. Mater., 2009, 19, 2431.

30 L. Qi, J. D. Sorge and D. P. Birnie III, J. Am. Ceram. Soc., 2009, 92, 1921.

31 H. Han, U. Bach, Y.-B. Cheng and R. A. Caruso, Appl. Phys. Lett., 2007, 90, 213510.

32 L. Schmidt-Mende and M. Grätzel, Thin Solid Films, 2006, 500, 296. 